\title{
Indicações e contra-indicações para o transplante hepático: saber para cuidar
}

\author{
Alexandra de Oliveira Matias Ferreira*
}

Enfermeira lider do CTI do Hospital Universitário Clementino Fraga Filho - UFRJ e Pós-graduanda do curso de enfermagem de alta complexidade com ênfase em CTI- UNIGRANRIO

\section{Resumo}

Esta revisão bibliográfica objetivou conhecer as doenças que causam a falência do fígado e as indicaçôes e contra-indicaçôes para o transplante de fígado. Prestar cuidados embasados em conhecimento científico faz parte da história de enfermagem. A partir deste, as intervenções de enfermagem poderão ser prestadas à luz dos principais sinais e sintomas.

Palavras-chave: transplante hepático, hepatopatias, história, enfermagem.

\section{Abstract \\ Indications and contraindications for liver transplantation: learn to care}

This literature review aimed to know diseases that cause liver failure and the indications and contraindications for transplantation. Providing nursing care based on scientific knowledge is included in nursing history. Starting from this knowledge, nursing interventions can be provided at light of the main signs and symptoms of liver diseases.

Key-words: liver transplantation, liver diseases, history, nursing.

\section{Resumen \\ Indicaciones y contraindicaciones para el trasplante hepático: saber para cuidar}

Esta investigación bibliográfica se propone conocer las enfermedades que causan falencia hepática y las indicaciones y contraindicaciones para el trasplante. Proporcionar cuidados de enfermería basada en el conocimiento científico forma parte del histórico de enfermería. A partir de este, las intervenciones de enfermería pueden ser prestadas frente a los principales signos y síntomas de las enfermedades del hígado.

Palabras-clave: trasplante de hígado, hepatopatías, história, Enfermería. 


\section{Introdução}

O transplante é um procedimento cirúrgico que consiste na troca de um órgão de uma pessoa doente (receptor) por outro normal de um doador. Pode-se recorrer ao doador vivo no caso de órgãos grandes ou duplos, tal como o fígado, que pode ser fracionado [1]. A característica principal do transplante, que o distingue de outras cirurgias, convertendo-o em uma terapêutica única e que alguns consideram como desvantagem, é a necessidade da utilização de órgáo ou tecido proveniente de um doador vivo ou falecido [2].

Atualmente, o transplante hepático é uma modalidade terapêutica utilizada com segurança em pacientes portadores de doenças hepáticas terminais ou em paciente que desenvolvem doenças hepáticas agudas graves. Devido a isso e ao aperfeiçoamento da técnica cirúrgica, à compreensão dos mecanismos imunológicos presentes no fenômeno da rejeição, ao uso da imunossupressáo e ao advento dos meios de conservação de órgão em soluçôes modernas, propiciaram o incremento desta técnica em todo o mundo e no Brasil [3].

Como forma de exemplificar esse avanço, o transplante hepático passou de uma técnica experimental, sem perspectivas reais de eficácia na década de 60, para uma técnica de excelência largamente utilizada nos dias de hoje. Mas, para que o transplante hepático se tornasse um procedimento confiável, o médico Thomas E. Starzl teve que demonstrar e confirmar para a comunidade científica que era uma técnica segura e eficiente [3].

Em 1983, Starzl conseguiu demonstrar para autoridades americanas, após anos de estudos, que o transplante de fígado apresentava resultados positivos para pacientes com hepatopatias terminais, pois, nesta época, já haviam sido realizados cerca de 500 transplantes com relativo sucesso. Diante de sua exposição, o procedimento deixava de ser experimental para ser um procedimento terapêutico. Dez anos depois, os procedimentos realizados ultrapassavam $10.000 \mathrm{em}$ todo mundo, como foi apresentado na Conferência Internacional, em Paris, no mesmo ano. Nesta conferência, constatou-se também que a confiança acerca do procedimento havia crescido: o aumento das filas de espera e a reduzida oferta de órgãos culminaram em vários óbitos na fila para tal procedimento [3].

O transplante é uma técnica eficaz nas hepatopatias crônicas e agudas graves e é considerado um dos maiores e mais complexos procedimentos da medicina. $\mathrm{O}$ paciente candidato ao transplante apresenta uma doença debilitante, que aumenta ainda mais o risco cirúrgico. No entanto, a mortalidade nos transplantes é muito menor do que a mortalidade entre os doentes que não se submetem ao procedimento [4].

O índice de sobrevida global para os pacientes transplantados está em torno de $80 \%$ aos três anos, após o procedimento. Sem ele, o índice de mortalidade com tratamentos conservadores ultrapassa $70 \%$ ao final de 12 anos. Portanto, o transplante é indicado para pacientes gravemente enfermos com várias co-morbidades relacionadas à perda gradual da funçáo hepática com elevado risco de morte, sendo a única opção terapêutica capaz de prevenir a morte certa em poucos meses, oferecendo a expectativa de uma nova vida $[3,5]$

A importância do transplante para a vida destes pacientes ficou evidente no estudo realizado por Parolin et al. [4], no qual foram entrevistados pacientes que se submeteram ao transplante hepático com sobrevida maior ou igual a nove meses, com boa perfusáo do enxerto e acompanhamento clínico regular. $\mathrm{O}$ resultado do estudo foi que 28 dos 41 pacientes entrevistados $(68,3 \%)$ retornaram às atividades laborais, sendo que 11 dos 28 pacientes $(39,3 \%)$ que retornaram ao trabalho após o transplante contribuíam ativamente para a renda da família; dos 13 pacientes que não retornaram ao trabalho, 5 foram por aposentaria precoce, 4 por desemprego, e 4 por incapacidade física. No entanto, quando estes pacientes foram questionados se poderiam voltar ao trabalho, $(100 \%)$ responderam que poderiam retornar por apresentarem boas condiçóes de saúde.

Neste estudo, com uma pequena amostra de uma realidade, ficou claro o impacto positivo na qualidade de vida do receptor. Além disso, por ser um procedimento que demanda considerável investimento técnico e financeiro, reintegrar o indivíduo em suas funçôes sociais é uma forma de retribuir à sociedade tal investimento [1].

O conhecimento técnico e a organização do serviço, decorrentes do aumento do número de transplantes, vêm facilitando a atuação do enfermeiro. A assistência ao paciente transplantado é altamente especializada, requerendo a atuação dos enfermeiros nas diversas fases do processo e exigindo pessoal capacitado [2].

O presente estudo partiu da minha inquietação a respeito das doenças que levam à falência 
progressiva do fígado. Trabalhando em um Centro de Terapia Intensiva (CTI), que recebe pacientes em pós-operatório imediato de transplantes hepáticos, percebi que era necessária maior compreensão acerca das doenças de base destes pacientes, pois muitas das complicaçóes que surgem nesta unidade têm relação direta com os efeitos deletérios crônicos de doenças tão devastadoras para o fígado. Saber das indicaçôes e o porquê das contra-indicações para tal procedimento é uma forma de prestar cuidados de enfermagem, pautadas em conhecimento científico direcionado, e com a finalidade de promover excelência no cuidado.

Como profissional da saúde comprometida com o bem-estar da população, urge a necessidade de divulgar algumas premissas básicas sobre transplante de fígado. As notícias divulgadas na imprensa a respeito da seriedade do programa de transplante hepático no Estado do Rio de Janeiro nos tornaram vulneráveis à generalizaçóes com outros profissionais. No entanto, não cabe aqui, o mérito de elucidar tais fatos, porém, este estudo tem como objetivos:

1) Clarificar quais são os critérios para um paciente ser incluído no programa de transplante hepático e como as doenças hepáticas deterioram a vidas desses pacientes;

2) Enfatizar a importância da doação.

\section{Material e métodos}

Este artigo é uma revisão bibliográfica, pois procura utilizar o conhecimento disponível em material publicado em diferentes registros, com a finalidade de auxiliar o pesquisador na compreensão das contribuiçóes teóricas acerca do tema. Ou seja, favorece o entendimento do que já é conhecido sobre o tópico em questão, além de concretizar os conhecimentos a respeito da temática [6,7].

A metodologia da pesquisa constituiu da consulta à base de dados Bdenf, Lilacs, e Medline para levantamento de artigos, dissertaçóes e teses sobre transplante hepático. Para tal, utilizou-se como palavras-chave: transplante hepático e transplante de fígado.

Foram listados cinco artigos indexados que correspondiam ao objetivo deste estudo. Além disso, foram excluídos três artigos, pois descreviam complicaçóes cirúrgicas no transplante hepático, custos do transplante hepático em um hospital do Paraná e perfil do transplante hepático na região norte do Brasil.

\section{Resultados e discussão}

\section{Indicação para o transplante}

A indicação para o transplante é complexa e só pode ser feita por um especialista mediante avaliação criteriosa, seguindo protocolos internacionais ou através de padronizaçóes nacionais. Basicamente, a indicação tem por objetivo prolongar a vida do paciente, proporcionando satisfatória qualidade de vida e recuperação da capacidade de trabalho.

Para a eleição do momento mais adequado para a realização do transplante, é fundamental conhecer profundamente a história natural da doença e os fatores prognósticos envolvidos em cada caso. Há fatores que sabidamente pioram o prognóstico a médio e longo prazo, além de outras opçóes terapêuticas, clínicas e cirúrgicas que não se mostram eficazes no controle da doença $[1,6]$.

$\mathrm{Na}$ maioria dos casos, os eleitos são pacientes com função hepática comprometida com várias internaçôes e procedimentos. Esses pacientes, de uma forma geral, apresentam um complexo conjunto de características e complicaçóes, envolvendo desde aspectos relativos à esfera biológica até problemas psicológicos, sociais e econômicos [2].

Considera-se que os candidatos à espera do transplante hepático atendam a quatro requisitos fundamentais [3]:

a) estabelecimento de diagnóstico específico da doença;

b) demonstração inequívoca da gravidade da doença, mediante provas documentadas;

c) identificação de possível complicação que poderá prejudicar a sobrevida do paciente;

d) estimativa da sobrevida do paciente submetido ou não ao transplante.

Quadro I - Doenças específicas indicadas para o transplante hepático em adultos [3].

\begin{tabular}{|l|}
\hline Doenças Hepáticas Colestásticas Crônicas \\
a.1. Cirrose biliar primária \\
a.2. Cirrose biliar secundária \\
a.3. Colangite esclerosante primária \\
\hline Doenças Hepatocelulares Crônicas \\
b.1. Cirrose hepática de etiologia viral, inclusive hepa- \\
tite B e C \\
b.2. Cirrose hepática autoimune \\
b.3. Cirrose hepática por tóxicos ou chagas \\
b.4. Cirrose alcoólica \\
b.4. Cirrose criptogenética
\end{tabular}




\section{Doenças Hepáticas Metabólicas}

c. 1. Hemocromatose avançada, em fase cirrótica

c.2. Doença de Wilson

c.3. Deficiência de alta-1-antitripsina, em fase cirrótica

Doenças Hepáticas Vasculares

d.1. Síndrome de Budd-Chiari

d.2. Doença hepática veno-oclusiva

Tumor primário de fígado

Trauma

O Quadro I ilustra as doenças hepáticas específicas listadas em todo mundo. Porém, especificamente no Brasil, com o objetivo de padronizar a inclusão de pacientes em lista de espera, foram criados critérios gerais mínimos, hoje validados pelo Sistema Nacional de Transplantes (SNT). Sendo assim, têm prioridade no transplante de fígado os pacientes que possuam os seguintes diagnósticos de hepatopatia na seguinte ordem [8]:

Hepatopatia crônica com, pelo menos, uma das seguintes complicaçóes:

- hemorragia digestiva de alta repetição, com dois ou mais episódios distintos;

- ascite de difícil controle clínico;

- encefalopatia hepática ou porto-sistêmica;

- peritonite bacteriana espontânea;

- portador de anastomose porto-sistêmica intrahepática;

- síndrome hepato-renal;

- síndrome hepatopulmonar;

- queda significativa do estado geral;

- letargia.

Hepatopatia crônica classificada como childPugh B ou C (por pontuaçáo, independente de complicaçóes.

Cirrose biliar primária com pelo menos uma das seguintes condiçôes:

- prurido;

- deterioraçáo da qualidade de vida;

- indicação segundo o modelo matemático da clínica Mayo.

Colangite esclerosante primária, com pelo menos, uma das seguintes condiçôes:

- colangite recorrente com mais de um episódio;

- deterioração da qualidade de vida;

- indicação segundo o modelo matemático da clínica de Mayo.

Outras doenças colestáticas, pelos mesmos critérios para cirrose biliar primária.

Carcinoma hepatocelular (CHC) com nódulo de até $5 \mathrm{~cm}$ ou três nódulos menores de $3 \mathrm{~cm}$, limitado ao fígado.

Insuficiência hepática aguda, segundo os critérios de O'Grady ou Clichy.

A despeito destas doenças, a hepatite por vírus $\mathrm{B}$ e principalmente a $\mathrm{C}$, quando em fase cirrótica descompensada, representam atualmente a maior parte das indicaçóes para o transplante hepático. Estima-se que existem 100 a 200 milhóes de portadores de vírus $\mathrm{C}$ no mundo; destes, $60 \%$ a $85 \%$ progredirão para formas crônicas e $10 \%$ a $15 \%$ para cirrose em aproximadamente 20 anos.

Em um estudo realizado no Hospital Albert Einstein sobre qual doença de base que mais culminou em transplante desde a implantação da unidade de transplante, ficou demonstrado que, dos 128 pacientes transplantados até 2002, 72 (56,2\%) tiveram como doença de base a hepatite B ou C. Porém, é importante salientar que quase a totalidade desses pacientes tinha como etiologia cirrose por vírus $\mathrm{C}$ - 65 deles $(50,8 \%)$ [8].

Os mesmos autores citam que alguns trabalhos não conseguem demonstrar a reduçáo de sobrevida em pacientes transplantados por hepatite $B$ (desde que recebam profilaxia específica) e $\mathrm{C}$, quando comparados a pacientes transplantados de fígado por outras etiologias, justificando plenamente a indicação do transplante desses pacientes [9].

\section{Contra-indicaçóes para o transplante}

Uma vez identificado o paciente como candidato potencial ao transplante, parâmetros clínicos e bioquímicos devem ser pesquisados, a fim de que as funções de excreção e síntese, as alterações metabólicas e os distúrbios psicossociais possam ser avaliados para justificar o momento da realização do procedimento. Por outro lado, contra indicaçóes ao transplante hepático de ordem absoluta e relativa estáo bem definidas. Neste aspecto, convém salientar que, com o aumento da experiência clínica, as contra-indicações de ordem absoluta vêm diminuindo, enquanto que as contra-indicaçóes de ordem relativa vêm aumentando [1].

Quanto ao futuro do candidato potencial ao transplante, deve-se questionar a realização de cirurgias prévias ao transplante tais como derivações venosas no tratamento da hipertensão portal ou derivaçôes íleo-digestivas para controlar problemas biliares, uma vez que estes procedimentos dificultam tecnicamente a execuçáo do transplante, pela formação de aderências e neoformaçóes vasculares. 
Para Castro e Silva et al., as doenças que possuem contra-indicaçóes são listadas na no quadro II [3].

Quadro II - Contra-indicações ao transplante hepáti-

co.

\begin{tabular}{|l|} 
A. Contra-indicações absolutas \\
a.1. Metástase hepatobiliar ou em outros órgãos \\
a.2. Doença cardiopulmonar avançada \\
a.3. Infecção ativa extra-hepática \\
\hline B. Contra-indicações ao transplante relativas a \\
b.1. Etilismo ativo \\
b.2. Uso abusivo de drogas \\
b.3. Sorologia positiva para HIV \\
b.4. Positividade para replicação do vírus da hepatite B \\
b.5. Doença renal crônica avançada \\
\hline
\end{tabular}

\section{Conclusão}

Diante do exposto, o transplante hepático é, para muitos pacientes, a única chance de sobrevida. As frustrações, as incertezas e o risco iminente de morte, devido às complicaçóes relacionadas à falência do órgão, são deixados de lado, quando um novo órgão é colocado em seu corpo. Desta forma, o órgão antigo simboliza um período de vida infeliz e o órgão transplantado traz consigo um novo suspiro de vida, uma chance de viver de novo. Além disso, propicia ao paciente a chance de voltar a ter uma atividade laboral, ajudar na renda familiar, fazer planos para o futuro, enfim, viver novamente em sociedade.

A indicação para o transplante segue normas relacionadas ao diagnóstico da doença e o quanto o mesmo afeta a vida do paciente. Protocolos internacionais e nacionais universalizam as rotinas, proporcionando direitos igualitários a todos os cidadáos ao procedimento. As contra-indicaçôes são claras e devem ser rigorosamente atendidas, pois o paciente a ser transplantado tem que possuir condições mínimas para seguir a terapêutica. Ademais, o organismo deve ser capaz de recuperar-se e manter as funçôes do órgão.

Conhecer as doenças que causam falência do fígado faz parte do histórico de enfermagem e, a partir deste, as intervenções de enfermagem podem ser prestadas à luz do conhecimento científico com base nos principais sinais e sintomas. Muitos destes pacientes vão ser internados em enfermarias e unidades de terapia intensiva, e alguns não teráo a chance de serem transplantados. Aqueles que terão chance, às vezes, sofreram por tanto tempo com hepatopatias, que o órgão transplantado, a princípio, não será capaz de resolver disfunçôes tão graves.

Cabe ressaltar que a doação é um ato voluntário, gratuito e que depende basicamente de uma capacidade enorme de amar ao próximo. Qualquer ação que desvirtue da real funçáo desse ato deve ser rigorosamente denunciado. $\mathrm{O}$ transplante hepático é totalmente custeado pelo SUS, sendo acessível a qualquer cidadão brasileiro, tal direito é legítimo e concebido a todos, pela promulgação da constituição brasileira de 1988.

\section{Referências}

1. Mesquita COM. Transplante hepático pediátrico: experiência do hospital das clínicas da UFMG [Tese]. Belo Horizonte: Faculdade de Medicina, Universidade Federal de Minas Gerais; 2007.

1. Parolin MB, Coelho CU, Matias JEF, Puccinelli V, Jarabiza $\mathrm{R}$, Ioshii SO. Resultados do transplante hepático em portadores de hepatocarcinoma. Arq Gastroenterol 2001;38(4):216-20.

1. Castro e Silva JO, Sakarankutty AK, Oliveira GR, Pacheco E, Ramalho FS, Sasso KD. Transplante de fígado: indicação e sobrevida. Acta Cir Bras 2002;17(3):8391.

1. Freitas ACT. Transplante de fígado [online]. [citado 2008 Jun 15]. Disponível em URL: htpp://www. alexandrectf.com.br/fígado.htm

1. Massarolo MCKB, Kurcgant P. O vivencial dos enfermeiros no programa de transplante de fígado de um hospital público. Rev Latinoam Enferm 2000;8(4):6672.

1. Garcia VD. A política de transplantes no Brasil. Revista da AMRIGS 2006;50 (4):313-20.

1. Baptista MN. Metodologia de pesquisa em ciências: análise quantitativa e qualitativa. Rio de Janeiro: LTC; 2007.

1. Polit DF, Beck CT, Hungler BP. Fundamentos de pesquisa em enfermagem: método, avaliação e utilização. 5a ed. Porto Alegre: Artmed; 2004.

1. Ferra-Neto BH, Filho SPM, Rezende MB, Afonso RC. Transplante de fígado. In: Knobel E. Condutas no paciente grave. 3a ed. São Paulo: Atheneu; 2006. 